\title{
Article \\ One-Step Electrodeposition of Superhydrophobic Coating on 316L Stainless Steel
}

\author{
Andrea Zaffora (D), Francesco Di Franco *, Bartolomeo Megna (D) and Monica Santamaria
}

check for updates

Citation: Zaffora, A.; Di Franco, F.; Megna, B.; Santamaria, M. One-Step Electrodeposition of

Superhydrophobic Coating on 316L Stainless Steel. Metals 2021, 11, 1867. https://doi.org/10.3390/met11111867

Academic Editors: Frank Czerwinski, Tiziano Bellezze and Andrea Brenna

Received: 24 October 2021

Accepted: 18 November 2021

Published: 20 November 2021

Publisher's Note: MDPI stays neutral with regard to jurisdictional claims in published maps and institutional affiliations.

Copyright: (c) 2021 by the authors. Licensee MDPI, Basel, Switzerland. This article is an open access article distributed under the terms and conditions of the Creative Commons Attribution (CC BY) license (https:/ / creativecommons.org/licenses/by/ $4.0 /)$.
Dipartimento di Ingegneria, Università degli Studi di Palermo, Viale delle Scienze, Ed. 6, 90128 Palermo, Italy; andrea.zaffora@unipa.it (A.Z.); bartolomeo.megna@unipa.it (B.M.); monica.santamaria@unipa.it (M.S.)

* Correspondence: francesco.difranco@unipa.it

\begin{abstract}
Superhydrophobic coatings were fabricated through a one-step electrochemical process onto the surface of 316L stainless steel samples. The presence of hierarchical structures at micro/ nanoscale and manganese stearate into the coatings gave superhydrophobicity to the coating, with contact angle of $\sim 160^{\circ}$, and self-cleaning ability. Corrosion resistance of 316L samples was also assessed also after the electrodeposition process through Electrochemical Impedance Spectra recorded in an aqueous solution mimicking seawater condition.
\end{abstract}

Keywords: stainless steel; 316L; superhydrophobicity; self-cleaning; stearic acid; electrodeposition

\section{Introduction}

Over the last two decades, many methods have been studied to produce efficient superhydrophobic surfaces. These are distinguished by an extremely high contact angle (CA), usually higher than $150^{\circ}$, and usually are composed by hierarchical micro/nano structure with low surface energy [1-4]. Superhydrophobicity confers to the materials some features, such as anti-icing, anti-corrosion, anti-scaling, that are very important in many engineering applications, e.g., aerospace, marine, biomedical, civil, etc. Moreover, superhydrophobic surfaces can also have a self-cleaning ability [5,6], i.e., dust/particles can be easily removed with rolling water drops, which is not the case on very smooth surfaces. This feature can have important consequences whether the self-cleaning material is used for architectonical applications, reducing frequent and expensive maintenance or cleaning procedures. Furthermore, superhydrophobic surfaces reduce contact time between the substrate and the aggressive environment. This is very important for those materials as stainless steels (SSs) that are usually employed in aggressive environments, such as marine environments, and that can be easily contaminated by liquid or particles, reducing its efficiency. The fabrication of superhydrophobic surfaces on SSs has been carried out through different techniques, such as the deposition of silane groups $[7,8]$, coating modification by fluorination $[9,10]$, deposition of layered double hydroxides [11] or metallic coatings [12], or two-step anodic oxidation [13]. Regardless, each of these methods would rarely be implemented in actual surface treatment industries as fluorine compounds should be avoided due to their toxicity to humans and environments.

In this work, we present a one-step electrochemical process for the fabrication of superhydrophobic and self-cleaning SS 316L surface with excellent corrosion resistance tested in sea water mimicking environment. Superhydrophobic layer morphology was studied by Scanning Electron Microscopy (SEM) investigation and its composition was assessed through Fourier Transform Infrared Spectroscopy (FT-IR). Self-cleaning tests were carried out and corrosion resistance was confirmed through an electrochemical characterization carried out in $3.5 \% \mathrm{NaCl}$ aqueous solution. 


\section{Materials and Methods}

Austenitic stainless steel 316L (EN 1.4404) was supplied by Outokumpu with 2B G320 surface finishing and 24 as PRE (Pitting Resistance Equivalent). Its bulk composition comprises C (0.02 wt.\%), Cr (17.2 wt.\%), Ni (10.1 wt.\%), Mo (2.1 wt.\%), Mn (0.94 wt.\%), Si $(0.75 \mathrm{wt} . \%), \mathrm{P}(0.045 \mathrm{wt} . \%), \mathrm{S}(0.01 \mathrm{wt} . \%)$ and Fe (balance). Some of the rectangular samples $\left(3 \times 1.5 \mathrm{~cm}^{2}\right)$ were mechanically polished with grinding papers P500, P800, P1200 and P2400 and with a velvet cloth to obtain a mirror-like surface finishing. Then, SS samples were ultrasonically cleaned in acetone for $10 \mathrm{~min}$ and in deionized water for $10 \mathrm{~min}$.

An electrodeposition process was carried out in a bath containing dimethyl sulfoxide (DMSO, $\left.\left(\mathrm{CH}_{3}\right)_{2} \mathrm{SO}\right)$ or ethanol $\left(\mathrm{CH}_{3} \mathrm{CH}_{2} \mathrm{OH}\right)$ as solvent, manganese (II) chloride tetrahydrate $\left(\mathrm{MnCl}_{2} \cdot 4 \mathrm{H}_{2} \mathrm{O}\right)$ and stearic acid $\left(\mathrm{C}_{18} \mathrm{H}_{36} \mathrm{O}_{2}\right)$. Mn chloride and stearic acid were $0.05 \mathrm{M}$ and $0.1 \mathrm{M}$ in concentration, respectively. Bath temperature was maintained at $50{ }^{\circ} \mathrm{C}$ and no stirring action was applied. Electrodeposition was undertaken at $30 \mathrm{~V}$ in a two-electrode configuration with SS sample as cathode and $2 \mathrm{~Pb}$ sheets as anodes. Deposition time was 20, 40 or $60 \mathrm{~s}$. After the electrodeposition, covered samples were rinsed with ethanol and deionized water, and then dried at room temperature.

Contact angle was measured with a FTA 1000 instrument, using deionized water in droplets of $5 \mu \mathrm{L}$. Measurements were repeated three times in several positions of the samples surfaces and the reported contact angle value is the mean of the different values.

Samples morphology was investigated with a FEI Quanta 200 FEG SEM microscope coupled with Energy-Dispersive X-ray Spectrum (EDX) facility. Each sample was covered with a thin Au film deposited by sputtering before any investigation.

Self-cleaning tests were carried out by depositing on the surface of the samples ammonium biborate powder to mimic a contaminant and, subsequently, cleaning the surface by the movement of water droplets provided by using an injection syringe [11].

Electrochemical measurements were carried out in a three-electrode cell configuration, using SS samples as working electrode, a Pt net with high surface area as counter electrode and an $\mathrm{Ag} / \mathrm{AgCl} / \mathrm{KCl}(3 \mathrm{M})$ as reference electrode (0.197 V vs. Standard Hydrogen Electrode). The electrochemical characterization bath was an aqueous solution containing sodium chloride ( $\mathrm{NaCl}$, Sigma) with a concentration of $3.5 \mathrm{wt} . \%$ in order to mimic sea water. Electrochemical Impedance Spectra were collected at corrosion potential, $E_{\text {corr }}$, superimposing an ac signal of $10 \mathrm{mV}$ to the $d c$ component in the frequency range $100 \mathrm{kHz}-100 \mathrm{mHz}$. EIS data were then fitted using ZSimpWin software. All the electrochemical data were acquired through a Parstat 2263 connected to a computer.

\section{Results and Discussion}

\subsection{Morphology and Wettability}

All the samples, with different surface finishing, were treated with the electrodeposition process to make superhydrophobic coatings on 316L SS by changing solvent (DMSO or ethanol) and treatment time (20,40 and $60 \mathrm{~s})$. Soon after electrodeposition process, treated samples CA was measured according to the procedure described in Section 2. Figure 1a,b show CA values for the samples with mirror-like and 2B G320 surface finishing, respectively, as a function of electrodeposition time and electrolyte solvent.

First, it is clear that using DMSO as solvent leads to the fabrication of superhydrophobic surfaces on 316 LS samples with mirror surface finishing, with CA ranging between $154^{\circ}$ and $159^{\circ}$. In this case, the electrodeposition time does not have a significant effect on superhydrophibicity (i.e., CA value), although a longer treatment time (i.e., $60 \mathrm{~s}$ ) resulted in a less compact coating, which was prone to mechanical degradation. Conversely, coatings obtained with 20 and $40 \mathrm{~s}$ deposition times resulted in coatings that were compact and not prone to shattering. It is noteworthy to mention that, regardless of surface finishing, the electrodeposition process carried out in DMSO results in samples with a higher CA with respect to those obtained by using ethanol as solvent. In the latter case, 316L SS samples were only hydrophobic (i.e., with CA $>120^{\circ}$ ) with a treatment time $\geq 40 \mathrm{~s}$ in case of mirror surface finishing samples, and with a treatment time $=60 \mathrm{~s}$ in the case of samples 
with 2B G320 finishing. Overall analysis of the data reveals that it is possible to obtain superhydrophobic SS samples only by using DMSO as solvent for the electrodeposition process and that a mirror-like surface finishing leads to higher $C A$ values.

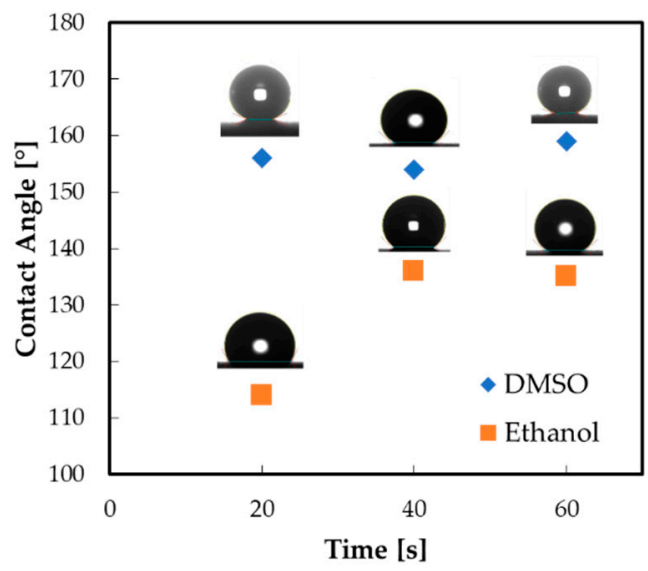

(a)

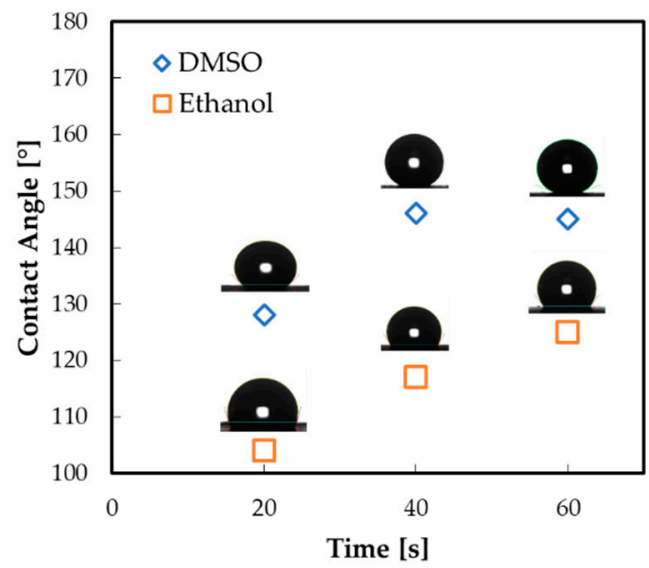

(b)

Figure 1. Contact angle values, as function of electrodeposition time, for SS samples after the electrodeposition process using two different solvents with (a) mirror-like and (b) 2B G320 surface finishing.

Morphologies of SS samples, treated for $40 \mathrm{~s}$ in DMSO and ethanol containing solutions, are shown in Figure 2a,b, respectively, where SEM micrographs are reported.

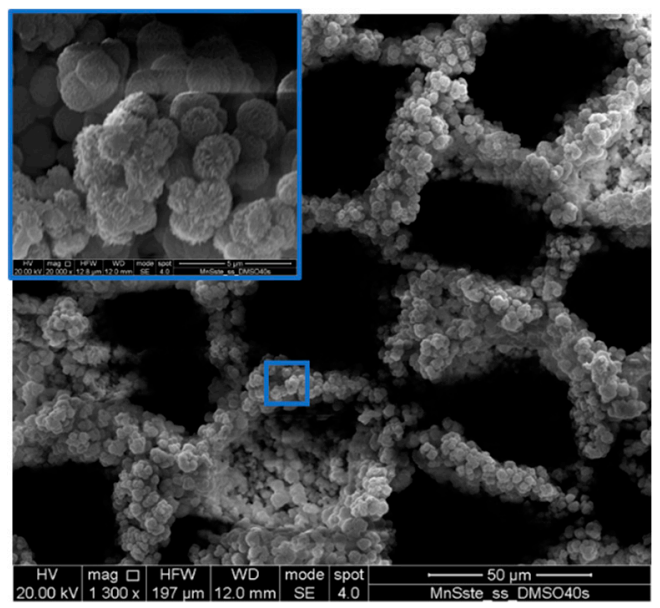

(a)

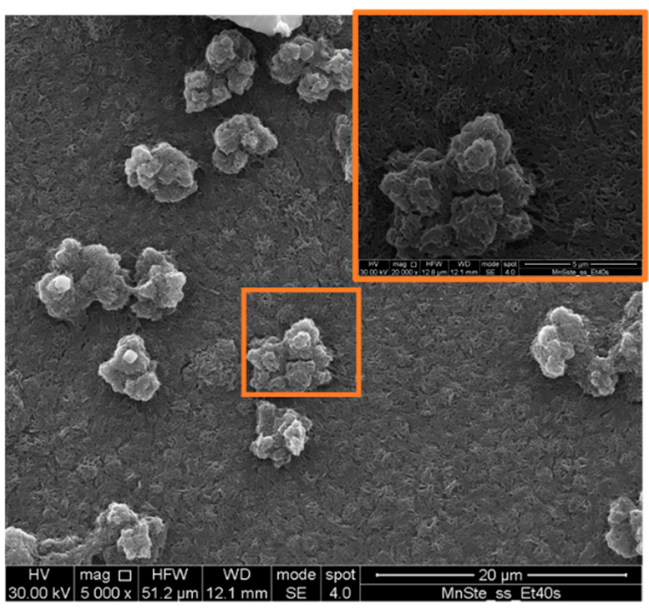

(b)

Figure 2. SEM micrographs of SS samples coated by using (a) DMSO and (b) Ethanol as solvent in the electrodeposition process. Inset: higher magnification SEM micrograph.

Regarding the SS sample treated in the bath containing DMSO as solvent, it is possible to distinguish a well-formed coating microstructure composed by voids (35-50 $\mu \mathrm{m}$ wide) surrounded by groups of hierarchical structures consisting of several microclusters of spherical particles as building units, as shown in the inset of Figure 2a. A completely different microstructure was assessed for the coating formed with the electrodeposition process carried out in the ethanol-containing solution. The surface is covered by nanoneedles that compact themselves in bigger structures that, regardless, do not cover the entire surface. This change in morphology is at the basis of the different hydrophobicity of the samples treated in DMSO rather than in ethanol. The microstructure that was formed during the electrodeposition process carried out in DMSO leads to an increase in surface roughness that is coherent with a Cassie-Baxter state [14]. In the latter, the air is entrapped into the 
voids that compose the coating microstructure, forming a water/air/solid contact that is essential to increase the hydrophobicity of the coating. Nevertheless, a high surface roughness is not enough to reach superhydrophobicity that can be achieved whether the coating has also a low surface energy. The latter can be efficiently obtained tailoring the composition of the coating. During the electrodeposition process carried out in organic solution containing a salt and a fatty acid, an organic compound comprising the anion deriving from the fatty acid and the cation deriving from the salt is deposited on the substrate lowering the surface energy. For this reason, manganese stearate is supposed to be deposited on the surface of 316L SS according to the following reaction mechanism [15]:

$$
\begin{gathered}
\mathrm{CH}_{3}\left(\mathrm{CH}_{2}\right)_{16} \mathrm{COOH} \leftrightarrow \mathrm{CH}_{3}\left(\mathrm{CH}_{2}\right)_{16} \mathrm{COO}^{-}+\mathrm{H}^{+} \\
\mathrm{Mn}^{2+}+2 \mathrm{CH}_{3}\left(\mathrm{CH}_{2}\right)_{16} \mathrm{COO}^{-} \rightarrow \mathrm{Mn}\left[\mathrm{CH}_{3}\left(\mathrm{CH}_{2}\right)_{16} \mathrm{COO}_{2} \downarrow\right. \\
2 \mathrm{H}^{+}+2 \mathrm{e}^{-} \rightarrow \mathrm{H}_{2} \uparrow
\end{gathered}
$$

Accompanying by hydrogen evolution due to the reduction of protons (see Equation (3)).

The results of FT-IR analysis are shown in Figure 3, where the comparison between the spectrum recorded for the coated SS sample and that related to stearic acid powder is reported.

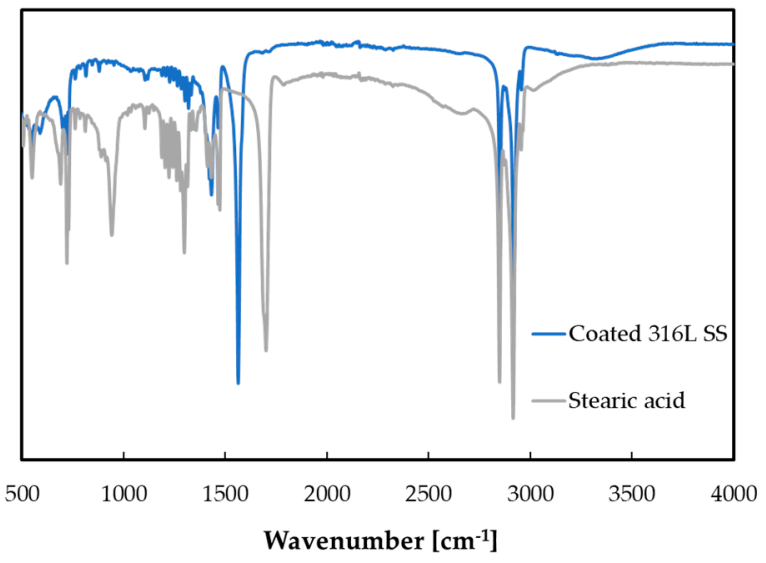

Figure 3. FT-IR spectra of coated SS samples and stearic acid powder.

Absorption bands at $2914 \mathrm{~cm}^{-1}$ and $2847 \mathrm{~cm}^{-1}$ are present in both spectra and they can be attributed to - $\mathrm{CH}$ - asymmetric and symmetric stretch vibration, respectively [16,17]. Thus, the coating fabricated through electrodeposition contains these C-based groups. Absorption band at $1699 \mathrm{~cm}^{-1}$ is present only in the spectrum related to the stearic acid. This band that can be associated with carboxyl group (-COO-) of the stearic acid. The absorption bands at $1563 \mathrm{~cm}^{-1}$ and $1430 \mathrm{~cm}^{-1}$, detected in the spectrum related to the coated SS sample, are associated with the symmetric and asymmetric stretches of the coordinated -COO- moieties [18], thus they are related to the presence of a salt of the stearic acid. The presence of Mn into the coating (as detected from EDX analysis) leads to the conclusion that, during the electrodeposition process, manganese stearate $\left(\mathrm{Mn}\left[\mathrm{CH}_{3}\left(\mathrm{CH}_{2}\right)_{16} \mathrm{COO}_{2}\right)\right.$ coating forms, regardless on deposition time.

Once (super)hydrophobicity was assessed, self-cleaning tests were carried out, since the self-cleaning property is effective in protecting metal surfaces from possible aggressive agents and in keeping SS surface in good condition, so that aesthetic appearance is maintained. Figure $4 \mathrm{a}$, b show self-cleaning tests for not treated 316L SS samples with mirror and 2B G320 surface finishing, respectively. 


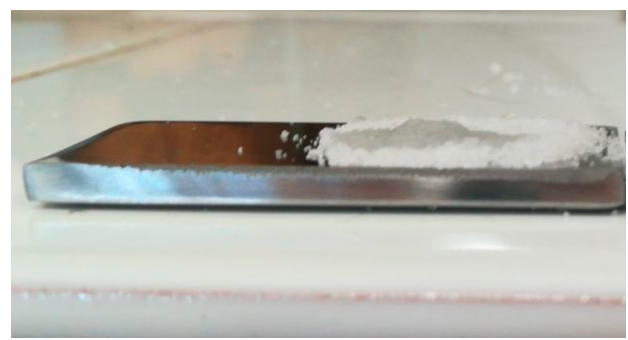

(a)

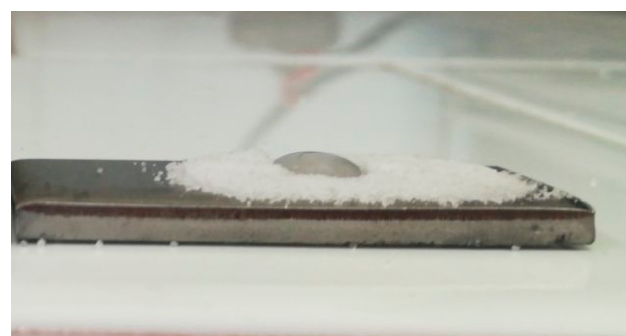

(b)

Figure 4. Self-cleaning test of the SS samples with (a) mirror-like and (b) 2B G320 surface finishing before electrodeposition process.

As it is possible to see, in the case of mirror surface finishing (see Figure 4a) water droplet expands on the surface, not removing ammonium biborate powder that was used to mimic usual dust. In the case of SS sample with 2B G320 surface finishing (see Figure $4 \mathrm{~b}$ ), water droplet compacts dust deposit enhancing its adhesion to the substrate surface. Self-cleaning tests related to SS samples after the electrodeposition process are shown in Figure 5a-c.

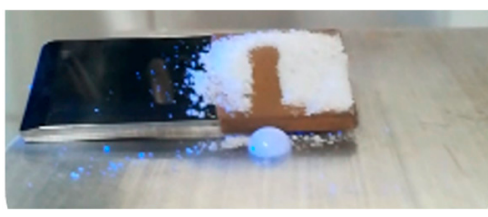

(a)

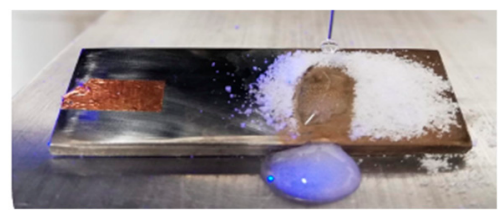

(b)

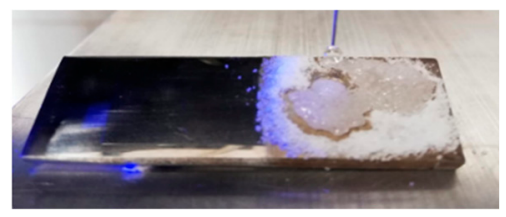

(c)

Figure 5. Self-cleaning test for SS samples treated in (a) DMSO-containing solution and in (b) ethanol-containing solution. (c) Self-cleaning test of the SS sample treated in ethanol-containing solution with an electrodeposition time of $20 \mathrm{~s}$.

All the samples treated in DMSO-containing solution have a self-cleaning property (as seen in Figure 5a), regardless of deposition time. In fact, soon after a water droplet touches the surface, it is removed from the surface, dragging the dust away. These results are in accordance with the formation of a Cassie-Baxter state, which is more effective than a Wenzel state to attain self-cleaning properties. The same can be stated for SS samples treated in ethanol-containing solution with deposition time $\geq 40 \mathrm{~s}$, as shown in Figure $5 \mathrm{~b}$ for the sample deposited for $40 \mathrm{~s}$. Conversely, the sample treated in ethanol-containing solution for $20 \mathrm{~s}$ does not show self-cleaning property, in agreement with the lower measured CA (see Figure 5c).

\subsection{Corrosion Tests}

Superhydrophobicity and self-cleaning properties are very important features for SS used for structural/architectonical applications only if the corrosion resistance of the steels is not compromised after the electrodeposition of the coating. For this reason, we carried out EIS spectra to assess the corrosion resistance of SS 316L samples before and after the electrodeposition treatment in a solution mimicking sea water. In Figure 6a,b, we report EIS spectra in the Nyquist representation (i.e., $Z_{\mathrm{Re}}$ vs. $-Z_{\mathrm{Im}}$ graphs) related to mirror finished SS 316L samples treated in DMSO and ethanol-containing solutions, respectively, with different electrodeposition times, recorded at corresponding corrosion potential. 


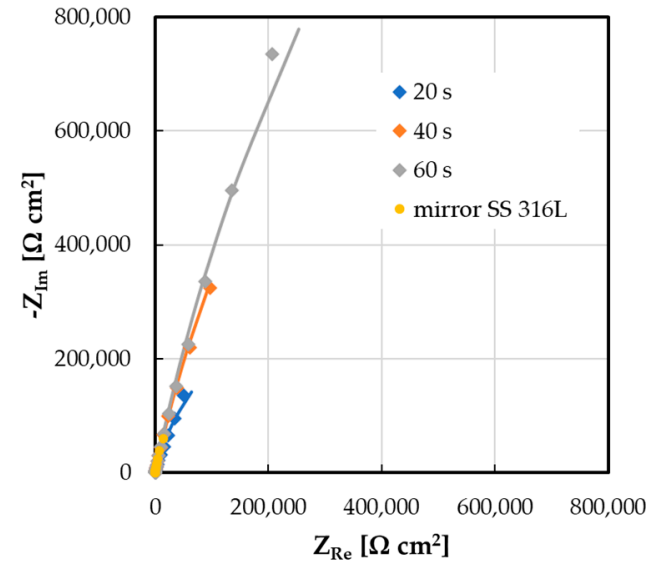

(a)

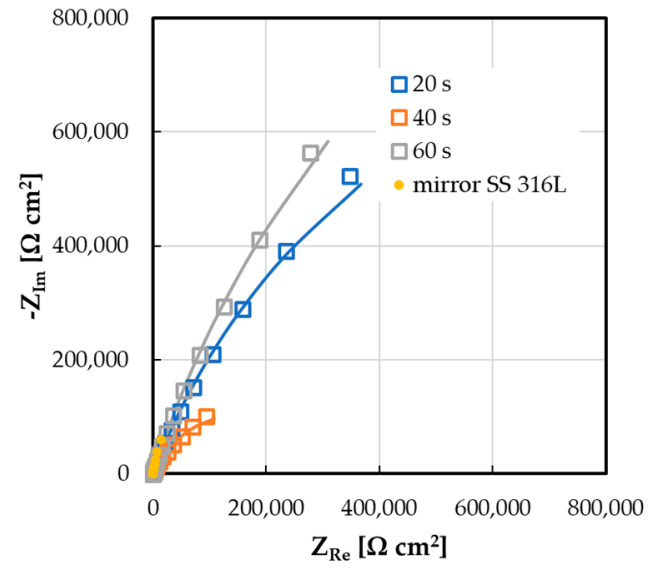

(b)

Figure 6. EIS spectra, recorded at corrosion potential, in Nyquist representation related to SS 316L samples after electrodeposition process with different treatment times. Solvent used: (a) DMSO; (b) Ethanol. Continuous lines: fitting lines.

Impedance spectra related to all the samples, regardless on solvent used during the electrodeposition and treatment time, look similar to portions of depressed semicircles. The electrical equivalent circuit that suitably models the electrochemical behaviour of the SS samples after electrodeposition is reported in Figure 7, i.e., the electrolyte resistance, $R_{\mathrm{el}}$, in series with a parallel ( $R_{\text {coat }} Q_{\text {coat }}$ ) [19-21] related to the behaviour of the superhydrophobic coating.

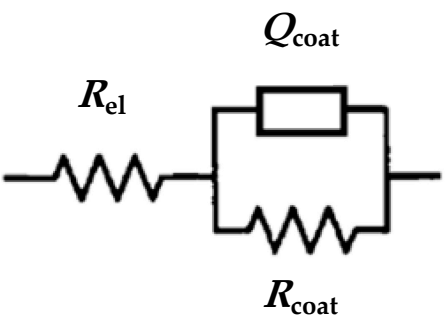

Figure 7. Electrical equivalent circuit used to fit impedance spectra shown in Figure 6a,b.

In particular, $Q_{\text {coat }}$ is a Constant Phase Element, $\mathrm{CPE}$, that was used to take into account the non-ideal capacitive behaviour of the superhydrophobic coating. EIS fitting parameters are reported in Table 1. In the case of the SS 316L sample with mirror surface finishing, the parallel (RQ) is related to the passive film grown on the steel by air exposure.

Table 1. Fitting parameters related to EIS spectra reported in Figure 6a,b. In the case of the mirror-finished sample, the resistance and the CPE are $R_{\mathrm{ox}}$ and $Q_{\mathrm{ox}}$, respectively.

\begin{tabular}{ccccccc}
\hline Solvent & $\begin{array}{c}\text { Electrodeposition Time } \\
(\mathbf{s})\end{array}$ & $\begin{array}{c}\boldsymbol{R}_{\mathbf{e l}} \\
\left(\boldsymbol{\Omega} \mathbf{~ c m}^{\mathbf{2}}\right)\end{array}$ & $\begin{array}{c}\boldsymbol{R}_{\mathbf{c o a t}} \\
\left(\mathbf{\Omega ~ c m}^{\mathbf{2}}\right)\end{array}$ & $\begin{array}{c}Q_{\text {coat }} \\
\left(\mathbf{S ~ s}_{\mathbf{n}} \mathbf{~ c m}^{-2}\right)\end{array}$ & $\mathbf{n}$ & $\chi^{\mathbf{2}}$ \\
\hline Mirror-finished sample & - & 20 & $6.0 \times 10^{5}$ & $2.5 \times 10^{-5}$ & 0.92 & $2.5 \times 10^{-3}$ \\
\hline \multirow{2}{*}{ DMSO } & 20 & 32 & $7.7 \times 10^{5}$ & $8.9 \times 10^{-6}$ & 0.86 & $7.2 \times 10^{-3}$ \\
& 40 & 40 & $4.7 \times 10^{6}$ & $4.3 \times 10^{-6}$ & 0.87 & $1.4 \times 10^{-2}$ \\
& 60 & 50 & $6.8 \times 10^{6}$ & $1.8 \times 10^{-6}$ & 0.87 & $2.9 \times 10^{-3}$ \\
\hline \multirow{2}{*}{ Ethanol } & 20 & 36 & $2.2 \times 10^{6}$ & $2.0 \times 10^{-6}$ & 0.77 & $1.1 \times 10^{-2}$ \\
& 40 & 37 & $3.1 \times 10^{5}$ & $2.4 \times 10^{-6}$ & 0.74 & $1.4 \times 10^{-2}$ \\
& 60 & 43 & $3.5 \times 10^{6}$ & $2.0 \times 10^{-6}$ & 0.80 & $4.3 \times 10^{-3}$ \\
\hline
\end{tabular}


As it is possible to note, the overall impedance keeps values in the order of $10^{6} \Omega \mathrm{cm}^{2}$, therefore the corrosion resistance to an aggressive environment, as the solution of $\mathrm{NaCl}$ mimicking seawater, is still maintained after the deposition of the superhydrophobic coating. After the electrochemical characterization, contact angle of the treated samples was measured, keeping values higher than $135^{\circ}$, i.e., maintaining a strong hydrophobic behaviour. Furthermore, this coating was successfully applied also on anodized AA5083 alloy retaining a CA higher than $120^{\circ}$ after 20 days of immersion in the same solution [15]. Anyway, future studies are needed to further address the study of the coating stability during long-term contact in seawater mimicking solution [22].

\section{Conclusions}

A one-step electrochemical process was proposed to grow a superhydrophobic coating onto the surface of SS 316L samples. Superhydrophobicity (highest contact angle $=159^{\circ}$ ) was reached by using DMSO as solvent in the electrodeposition solution and mirror-like 316L surface finishing, whilst the usage of ethanol as solvent and as-supplied steel samples led to hydrophobic coatings. The morphology of the coatings was composed by hierarchical micro- and nanostructures whenever DMSO was used. The combination of hierarchical structures and low surface energy, due to the presence of a salt of stearic acid in the coating, resulted in a superhydrophobic surface. The self-cleaning property was also assessed, with the possibility of easily removing scaling from the surface.

Electrochemical measurements demonstrated the maintained corrosion resistance of the SS 316L samples in a seawater mimicking solution also after the electrodeposition process. In this way, an anti-corrosion and self-cleaning coating was fabricated onto the surface of SS 316L, which is expected to extend the service life of stainless steel parts, reducing the need for maintenance and cleaning procedures.

Author Contributions: Conceptualization, A.Z. and M.S.; methodology, A.Z., F.D.F. and M.S.; formal analysis, A.Z.; investigation, A.Z. and B.M.; data curation, F.D.F. and A.Z.; writing-original draft preparation, A.Z.; writing-review and editing, A.Z., F.D.F., B.M. and M.S.; visualization, A.Z., F.D.F. and M.S.; supervision, A.Z. and M.S.; resources, M.S. All authors have read and agreed to the published version of the manuscript.

Funding: This research received no external funding.

Acknowledgments: Authors gratefully acknowledge Outokumpu for providing stainless steel samples.

Conflicts of Interest: The authors declare no conflict of interest.

\section{References}

1. Tian, X.; Verho, T.; Ras, R.H.A. Moving superhydrophobic surfaces toward real-world applications. Science 2016, 352, 142-143. [CrossRef] [PubMed]

2. Liu, M.; Wang, S.; Jiang, L. Nature-inspired superwettability systems. Nat. Rev. Mater. 2017, 2, 1-17. [CrossRef]

3. Barati Darband, G.; Aliofkhazraei, M.; Khorsand, S.; Sokhanvar, S.; Kaboli, A. Science and Engineering of Superhydrophobic Surfaces: Review of Corrosion Resistance, Chemical and Mechanical Stability. Arab. J. Chem. 2020, 13, 1763-1802. [CrossRef]

4. Wang, F.; Pi, J.; Song, F.; Feng, R.; Xu, C.; Wang, X.L.; Wang, Y.Z. A superhydrophobic coating to create multi-functional materials with mechanical/chemical/physical robustness. Chem. Eng. J. 2020, 381, 122539. [CrossRef]

5. Ren, T.; He, J. Substrate-versatile approach to robust antireflective and superhydrophobic coatings with excellent self-cleaning property in varied environments. ACS Appl. Mater. Interfaces 2017, 9, 34367-34376. [CrossRef]

6. Guan, Y.; Yu, C.; Zhu, J.; Yang, R.; Li, X.; Wei, D.; Xu, X. Design and fabrication of vapor-induced superhydrophobic surfaces obtained from polyethylene wax and silica nanoparticles in hierarchical structures. RSC Adv. 2018, 8, 25150-25158. [CrossRef]

7. Boinovich, L.B.; Emelyanenko, A.M.; Ivanov, V.K.; Pashinin, A.S. Durable icephobic coating for stainless steel. ACS Appl. Mater. Interfaces 2013, 5, 2549-2554. [CrossRef]

8. Gao, L.; Yang, S.; Yang, H.; Ma, T. One-Stage Method for Fabricating Superhydrophobic Stainless Steel Surface and Its AntiCorrosion Performance. Adv. Eng. Mater. 2017, 19, 1-6. [CrossRef]

9. Liang, J.; Li, D.; Wang, D.; Liu, K.; Chen, L. Preparation of stable superhydrophobic film on stainless steel substrate by a combined approach using electrodeposition and fluorinated modification. Appl. Surf. Sci. 2014, 293, 265-270. [CrossRef]

10. Li, H.; Yu, S.; Han, X.; Zhao, Y. A stable hierarchical superhydrophobic coating on pipeline steel surface with self-cleaning, anticorrosion, and anti-scaling properties. Colloids Surfaces A Physicochem. Eng. Asp. 2016, 503, 43-52. [CrossRef] 
11. Liu, P.; Zhang, Y.; Liu, S.; Zhang, Y.; Qu, L. Fabrication of superhydrophobic marigold shape LDH films on stainless steel meshes via in-situ growth for enhanced anti-corrosion and high efficiency oil-water separation. Appl. Clay Sci. $2019,182,105292$. [CrossRef]

12. Liu, E.; Yin, X.; Hu, J.; Yu, S.; Zhao, Y.; Xiong, W. Fabrication of a biomimetic hierarchical superhydrophobic Cu-Ni coating with self-cleaning and anti-corrosion properties. Colloids Surfaces A Physicochem. Eng. Asp. 2020, 586, 124223. [CrossRef]

13. Zhang, B.; Ni, H.; Chen, R.; Zhan, W.; Zhang, C.; Lei, R.; Zha, Y. A two-step anodic method to fabricate self-organised nanopore arrays on stainless steel. Appl. Surf. Sci. 2015, 351, 1161-1168. [CrossRef]

14. Nosonovsky, M.; Bhushan, B. Superhydrophobic surfaces and emerging applications: Non-adhesion, energy, green engineering. Curr. Opin. Colloid Interface Sci. 2009, 14, 270-280. [CrossRef]

15. Di Franco, F.; Zaffora, A.; Vassallo, P.; Santamaria, M. Double Step Electrochemical Process for the Deposition of Superhydrophobic Coatings for Enhanced Corrosion Resistance. J. Electrochem. Soc. 2021, 168, 101502. [CrossRef]

16. Zhang, B.; Li, J.; Zhao, X.; Hu, X.; Yang, L.; Wang, N.; Li, Y.; Hou, B. Biomimetic one step fabrication of manganese stearate superhydrophobic surface as an efficient barrier against marine corrosion and Chlorella vulgaris-induced biofouling. Chem. Eng. J. 2016, 306, 441-451. [CrossRef]

17. Zhang, B.; Zhu, Q.; Li, Y.; Hou, B. Facile fluorine-free one step fabrication of superhydrophobic aluminum surface towards self-cleaning and marine anticorrosion. Chem. Eng. J. 2018, 352, 625-633. [CrossRef]

18. Zhao, T.; Kang, Z. Simultaneously Fabricating Multifunctional Superhydrophobic/Superoleophilic Coatings by One-Step Electrodeposition Method on Cathodic and Anodic Magnesium Surfaces. J. Electrochem. Soc. 2016, 163, D628-D635. [CrossRef]

19. Orazem, M.E.; Tribollet, B. Electrochemical Impedance Spectroscopy; John Wiley \& Sons: Hoboken, NJ, USA, 2008 ; ISBN 9780470041406.

20. Zaffora, A.; Tranchida, G.; Di Franco, F.; Di Quarto, F.; Santamaria, M. Physico-Chemical Characterization of Anodic Oxides on Hf as a Function of the Anodizing Conditions. J. Electrochem. Soc. 2016, 163, C563-C570. [CrossRef]

21. Zaffora, A.; Di Quarto, F.; Kura, C.; Sato, Y.; Aoki, Y.; Habazaki, H.; Santamaria, M. Electrochemical Oxidation of Hf-Nb Alloys as a Valuable Route to Prepare Mixed Oxides of Tailored Dielectric Properties. Adv. Electron. Mater. 2018, 4, 1800006. [CrossRef]

22. Boinovich, L.B.; Emelyanenko, A.M. The behaviour of fluoro- and hydrocarbon surfactants used for fabrication of superhydrophobic coatings at solid/water interface. Colloids Surfaces A Physicochem. Eng. Asp. 2015, 481, 167-175. [CrossRef] 